\title{
Reconceptualizing BME Authentic Learning in the Age of COVID-19 and Remote Learning
}

\author{
Aileen Huang-Saad (iD, ${ }^{1}$ Rachael Schmedlen, ${ }^{1}$ Robert Sulewski, ${ }^{2}$ \\ and Karen SPRingSteEn ${ }^{2}$ \\ ${ }^{1}$ Biomedical Engineering, University of Michigan, Ann Arbor, MI, USA; and ${ }^{2}$ Technical Communication, University of \\ Michigan, Ann Arbor, MI, USA
}

(Received 29 June 2020; accepted 24 July 2020; published online 17 August 2020)

\section{CHALLENGE STATEMENT}

ENGR100 is the University of Michigan College of Engineering's first year engineering program designed to simulate a real-world engineering environment. Each year up to 28 sections of ENGR100 are offered, allowing students to experience the engineering profession in different subdisciplines. Many first-year students use this course to inform their career paths.

For the past 18 years, the Biomedical Engineering (BME) Department has been sponsoring ENGR100.500 (Biotechnology, Human Values, \& Engineering), focusing on the research and paper design of a novel molecular test for a disease, with two hands-on wet laboratory experiments. ${ }^{16}$ Unfortunately, the focus on diagnostics does not expose students to the breadth of opportunities in BME and thus may not allow students to develop a BME identity as reported by students in our department. Students in our department report longstanding challenges with their identity as biomedical engineers, ${ }^{18}$ and their perceptions of BME education and future career opportunities. ${ }^{1,10}$ Specifically, for our department ${ }^{9}$ :

- BME students often do not understand what BME is and have difficulty seeing how other engineering disciplines integrate in BME;

- BME students want early career guidance;

- the current BME curriculum is not traditionally adaptive to the changing needs of BME-in-practice; and,

Address correspondence to Aileen Huang-Saad, Biomedical Engineering, University of Michigan, Ann Arbor, MI, USA. Electronic mail: aileenhs@umich.edu
- BME students want more diverse, hands-on experiences specific to BME early in their academic careers.

The current COVID-19 pandemic offers a unique opportunity to reconsider the course content and hybrid course delivery, while addressing these longstanding challenges. The pandemic highlights how biomedical engineers can play a role in addressing the pandemic from scientific discovery, predictive modeling, diagnostics, therapeutics, device solutions, manufacturing, commercialization, and public health. Thus, in Fall 2020, we will offer a re-designed, ENG100.500 to address biomedical engineering and human values in the era of COVID-19. Acknowledging the importance of situated learning ${ }^{5}$ and motivation in student learning, ${ }^{4,12,13}$ we will use the authentic learning environment framework $^{8}$ to guide our new hybrid course design. Our specific goals include:

- broadening students' exposure to the scope of biomedical engineering beyond biotechnology to help them define the evolving discipline of biomedical engineering as they plan their careers;

- demonstrating the role of the engineering design process in healthcare; and

- assessing the hybrid learning model in which extensive in-person experimentation is limited.

\section{NOVEL INITIATIVE}

Introductory first year design classes ${ }^{17}$ and project based learning ${ }^{15}$ are not novel in today's engineering education environment. For this proposed course, the novelty lies in the: 
TABLE 1. Overview of course.

\begin{tabular}{|c|c|c|c|c|}
\hline & & Knowledge & Skills & Semester-long project \\
\hline \multirow{7}{*}{ Semester } & \multicolumn{4}{|c|}{ Phase I: Foundational Understanding } \\
\hline & What is engineering design? & $\begin{array}{l}\text { Engineering design process: } \\
\text { understand, explore, and } \\
\text { implement Contact Tracing } \\
\text { Solutions }\end{array}$ & $\begin{array}{l}\text { Front-end design skills } \\
\text { (interviewing, stakeholder } \\
\text { maps, ecosystems) }\end{array}$ & \multirow{6}{*}{$\begin{array}{l}\text { Work in teams to use } \\
\text { course developed } \\
\text { skills to develop a } \\
\text { healthcare solution } \\
\text { for clinical sponsors }\end{array}$} \\
\hline & What is COVID-19? & $\begin{array}{l}\text { Epidemiology, symptoms, and } \\
\text { treatment of COVID-19 }\end{array}$ & $\begin{array}{l}\text { Reading and interpreting } \\
\text { scientific papers }\end{array}$ & \\
\hline & \multicolumn{3}{|c|}{ Phase II: COVID-19 Case Studies } & \\
\hline & Medical diagnostics & Diagnosing COVID 19 & $\begin{array}{l}\text { Gene expression testing (e.g., } \\
\text { biomarker selection and } \\
\text { detection, specificity and } \\
\text { sensitivity) }\end{array}$ & \\
\hline & Patient monitoring & $\begin{array}{l}\text { Oxygen saturation and } \\
\text { COVID-19 }\end{array}$ & $\begin{array}{l}\text { Microprocessors and sensors } \\
\text { (Arduinos) }\end{array}$ & \\
\hline & Medical devices & PPEs and infection control & $\begin{array}{l}\text { Computer aided design } \\
\text { (Fusion360) }\end{array}$ & \\
\hline
\end{tabular}

1 Explicit application of the authentic learning environment framework to BME course design;

2 Creation of a course focused on the role BMEs play in healthcare in the context of COVID-19;

3 Scaffolding the design course to reinforce the role of engineering design and problem solving in BME;

4 The integration of technical communication skill development in the context of COVID-19; and,

5 The shift to ensuring remote design hands-on learning opportunities and deliberate development of specific knowledge and skills.

The concept of authentic learning environments is grounded in situated cognition theory ${ }^{5}$ which postulates that learning is social and often occurs through shared activities, language and problem solving. Authentic learning is at the core of engineering design classes through project-based learning, but with the recent pandemic and significant migration to online learning, instructors need to be even more deliberate in cultivating an authentic learning environment. With this in mind, we explicitly created this first-year design class using the authentic learning environment framework. The authentic learning environment framework consists of 9 elements $^{8}$ : authentic context, authentic tasks, access to experts, multiple roles and perspectives, collaborative construction of knowledge, reflection, articulation, and coaching and scaffolding.

\section{Course Overview and Design Thread}

The purpose of this course is to introduce early career engineering students to $\mathrm{BME}$ in practice in the context of COVID-19 while developing specific knowledge and skills. COVID-19 was selected as the authentic context to increase student motivation and authentic learning. In support of the authentic context, students will be required to communicate their work through mediums employed in industry, e.g., delivering reports in memo format and learning how to write executive summaries. All examples and case projects will be related to COVID-19. Similar to traditional design classes, students will be placed in teams and work with clinical faculty to identify a healthcare problem that can be solved using the engineering design process, computer aided design, expression testing, and/or microprocessors (authentic task). Concurrently, students will explicitly engage in specific skill development in the context of COVID-19 (Table 1). We will use a strategic blend of asynchronous and synchronous delivery to accommodate students in different time zones, with different internet access, and locations.

The semester course will be separated into two phases, Foundational Understanding and COVID-19 Case Studies. During the Foundational Understanding Phase, students will be introduced to the design process and COVID-19. In exploring the design process, students will make use of front-end design tools that facilitate understanding and exploring healthcare problems. While there are many interpretations of the design process, ${ }^{6}$ the process can be generalized as iterative and consisting of three general stages: understanding, exploring, and implementing. To understand a problem, engineers must be able to clarify and define the problem, determine relevant stakeholders, understand stakeholder needs, identify prior solutions, and determine relevant criteria to be met to solve a prob- 
TABLE 2. Elements of practice as related to nine aspects of an authentic learning environment.

Elements of an Authentic Learning

Environment

Authentic context

Authentic tasks

Access to expert performances and modeling of processes

Multiple roles and perspectives

Collaborative construction of knowledge

Reflection

Articulation

Coaching and scaffolding

Authentic assessment
Elements in Practice

The course will focus on three different case studies and a semester long team project. The case students will challenge students to develop skills in computer aided design, microprocessors and molecular diagnostics such that these skills can be applied to their semester long project. For each case, students will be tasked with a COVID specific design problem as they develop their technical skill: (1) CAD design of a medical instruments, (2) construction of a pulse oximeter, and (3) gene expression for medical diagnostics. The semester long project will require the development of a prototype and professional communications expected in industry (e.g., memorandums and executive summaries)

BME design alumni and clinical sponsors will be consultants to the teams, offering feedback and just in time consulting as they explore their solution space. Students will be guided in how to identify appropriate alumni to approach, establish contact, and engage in an online meeting

The course is team taught, including two BME faculty with expertise in different areas, and two technical communications faculty, one of whom has a doctorate in pharmacy

Students will work in teams to develop a healthcare solution for a clinical sponsor. Students will have at least 3 online meetings with their clinical sponsors and use their front-end design tools (interviewing, stakeholder maps, etc.) to understand and explore the problem and get feedback for iteration on their proposed solutions

Reflective exercises will be integrated into each case assignment to not only reflect on the specific case but compare and contrast the design process across cases. While each case study will be delivered asynchronously, providing students access flexibility, lectures will be paired with engagement assignments that ask students to reflect on questions posed to the students throughout the asynchronous lecture. Instructors will be able to use student responses for identifying muddiest points and just in time teaching ${ }^{3}$

Students will have individual assignments for each case study where they will be required to articulate their findings and reflections. Additionally, students will be responsible for at least one laboratory report, two oral presentations, a progress report, and a final report for their team clinical project

The entire course is scaffolded to reinforce the importance of the design process in BME. At the beginning of the course, students will be introduced to the design process with respect to contact tracing. The following three cases will each be discussed with respect to the design process

Technical skills assessment will be directly associated with the successful solution of each task related to each case using CAD, microprocessors, and gene expression. Students will also be assessed for the successful development of a healthcare solution for their clinical sponsor

Communication skills will be assessed through written reports (progress and final) and oral presentations. Teamwork will be assessed by the two team peer evaluations and the final team assessment report

lem. For exploration, engineers conceptualize numerous candidate solutions, assess these solutions vis-à-vis their criteria and stakeholder feedback, and ultimately select a potential design. Finally, engineering tools are used to implement their solutions.

Students will learn about front-end design by engaging in an active learning design problem focused on contact tracing for COVID-19, where they will practice interviewing skills and develop stakeholder and ecosystem maps. Contact tracing was selected so that students can practice front-end design skills from remote locations. Contact tracing is a universal problem that is relevant to the students' lived experiences and impacts everyone in their personal ecosystems, classmates, family members, etc. In introducing COVID-19, students will also participate in a workshop focused on reading and interpreting scientific papers.

During the COVID-19 Case Studies Phase, students will explore three different case studies, delivered in the framework of the design process. Each case will be presented such that students first seek to understand the biomedical engineering context, explore potential solutions, and implement solutions with the new technical skills introduced in the course. Specifically, the cases will address solving the problem of limited per- 
sonal protective equipment with computer aided design, diagnosing COVID-19 with expression testing, and monitoring patient oxygen saturation with microprocessors and sensors. The three technical skills can be developed remotely. Students will be introduced to Fusion360 for computer aided design, which is available to students at no cost. Each student will be given an Arduino design kit to build a pulse oximeter in their own space. Finally, expression testing is a wet lab experiment that can be done in small groups with social distancing, while a remote alternative could include virtual observation of the experiment with remote data analysis. Consistent use of the design process will reaffirm how the design process, as applied to healthcare, uniquely defines biomedical engineers.

\section{Cultivating the Authentic Learning Environment Online}

While context and tasks are critical for authentic learning, the social aspect of learning may be lost in an online environment. Thus, we will explicitly cultivate all elements of an authentic learning environment. The reality of the current pandemic suggests that the professional workforce must become adept at extended periods of online interactions and working in remote teams. Thus, students will be held accountable for individual and group deliverables as would be expected in a professional environment. We anticipate at least 70 students to enroll in the course. As result, knowledge and skills content will be delivered synchronously with embedded reflection exercises for instructors to monitor status of student learning and interject just-intime teaching modules. Sessions will also be recorded for asynchronous access. Concurrently, students will be required to participate in at least 4-6 synchronous discussion sections throughout the semester $(\sim 20$ per section), as would be expected in professional environments, to develop community, form strong project teams, and a create a sense of accountability. A course Slack channel will also be created to support asynchronous communication. In Table 2, we specifically list the nine elements of an authentic learning environment and how the elements will be addressed in practice.

\section{Reflection}

Success of our hybrid COVID-19 focused first year course will be explored with respect to student motivation and student understanding of biomedical engineering in practice. Specifically, we will ask, (1) How do students' motivation for biomedical engineering change with course enrollment; and (2) How do student's understanding of biomedical engineering in practice change with course enrollment? Glynn et al.'s
Science Motivation Questionnaire II (SMQII) will be adapted to measure student biomedical engineering motivation. ${ }^{7}$ The SMQII is a validated measure developed from the perspective of social cognitive career theory and assesses five motivation components: intrinsic motivation, self-determination, self-efficacy, career motivation, and grade motivation. ${ }^{7}$ Concept mapping and an identity survey adapted from the work of Peters ${ }^{11}$ and Ramo et al. ${ }^{14}$ will be used to explore changes in students' understanding of BME professional practice and perception of identity. Concept mapping is a visual, holistic approach students can use to represent their understanding of a field and can be used to assess knowledge integration. ${ }^{2}$ At the beginning of the course, students will be asked to complete the SMQII and identity surveys and will participate in a concept map activity to establish a baseline of the students understanding of BME in practice. Students will complete the same activities at the completion of the course. Survey results will be analyzed for validity and reliability prior to pre/post data analysis. Concept maps will be scored holistically, taking into account comprehensiveness, organization, and correctness. ${ }^{2}$

\section{The Reality of the Time}

It is important to note that the authors acknowledge the challenge of the current pandemic and increased pressures to all involved, from students to instructors to alumni and clinical sponsors. The course historically has involved clinical sponsors and in respect of their time we reached out to them early in the summer to see if they would still be interested in participating and if they had COVID-19 specific problems for students to address. It was to the authors' surprise that many clinical sponsors still wanted to participate. In fact, many clinical sponsors, previous and new, were motivated to participate because of the focus on COVID-19 and their personal interests in addressing these relevant critical problems. We have also been very prescriptive of the project and process so as to not overburden the clinical sponsor and teams:

1 Projects are defined by the clinical sponsor and vetted by the teaching team: Given the short timeframe and the limited skills expected of first year students, needs finding is not a part of these projects and projects are vetted for alignment with skills developed in the course.

2 Time limited: When recruiting clinical sponsors, we asked for a minimum of 2 virtual meetings over the course of the semester and email communication, estimating approximately 10 hours of time over 14 weeks. The teaching team will take on the responsibility of guiding students through the 
design process so that meetings with clinical sponsors are focused and targeted for clinical and project specific questions.

3 Access to experts: Recognizing the burden of students requesting meetings, we are reaching out to BME alumni to create a list of willing and interested alumni.

4 Code of conduct: This first-year course is part of a college wide first year program that seeks to integrate technical communications into the course. As a part of that, students will receive instruction on professional conduct and how to interact with stakeholders and peers.

Finally, we recognize potential difficulties with execution. By using the authentic learning framework, we were able to develop a roadmap for creating an authentic environment. At the same time, this roadmap helps us identify what can be excluded should we find the need to reduce interventions in real time.

\section{ACKNOWLEDGMENTS}

Course revisions were informed by material developed in the National Science Foundation funded BME Instructional Incubator (NSF-EEC-1825669).

\section{AUTHOR CONTRIBUTIONS}

AH-S penned the first version of the manuscript and course revision. RS taught the previous version of the course and worked with AH-S to refine the course content. RS has been part of the course teaching team for the past 15 years and helped refine the course content. KS helped edit the manuscript. All four will be instructors in the fall course, AH-S and RS will be the BME instructors and RS and KS are responsible for technical communications. RS will also be responsible for the expression testing laboratory.

\section{REFERENCES}

\footnotetext{
${ }^{1}$ Berglund J. The real world: BME graduates reflect on whether universities are providing adequate preparation for a career in industry. IEEE Pulse. 2015;6:46-9.

${ }^{2}$ Besterfield-Sacre M, Gerchak J, Lyons MR, Shuman LJ, Wolfe H. Scoring concept maps: An integrated rubric for assessing engineering education. $\mathbf{J}$ Eng Educ. 2004;93(2):105-15.
}

${ }^{3}$ Borrego M, Cutler S, Prince M, Henderson C, Froyd JE. Fidelity of implementation of research-based instructional strategies (RBIS) in engineering science courses. J Eng Educ. 2013;102(3):394-425.

${ }^{4}$ Brophy J. Conceptualizing student motivation. Educ Psychol. 1983;18(3):200-15.

${ }^{5}$ Brown JS, Collins A, Duguid P. Situated cognition and the culture of learning. Educ Res. 1989;18:32-42.

${ }^{6}$ Cross N. Engineering design methods, vol. 12. Chichester: Wiley; 2008. p. 217.

${ }^{7}$ Glynn SM, Brickman P, Armstrong N, Taasoobshirazi G. Science motivation questionnaire II: validation with science majors and nonscience majors. J Res Sci Teach. 2011;48(10):1159-76.

${ }^{8}$ Herrington J, Reeves TC, Oliver R. Authentic learning environments. In: Spector JM, Merrill MD, Len J, Bishop MJ, editors. Handbook of research on educational communications and technology. New York: Routledge; 2004. p. 401-13.

${ }^{9}$ Huang-Saad A, Stegemann J, Shea L. Developing a model for integrating professional practice and evidence-based teaching practices into BME curriculum. Ann Biomed Eng. 2020;48(2):881-92.

${ }^{10}$ Nocera TM, Ortiz-Rosario A, Shermadou A, Delaine DA. How do biomedical engineering graduates differ from other engineers? Bridging the gap between BME and industry: a case study. In: ASEE annual conference \& exposition, conferences and proceedings, 2018.

${ }^{11}$ Peters A-K. Learning computing at university: participation and identity. Digital comprehensive summaries of Uppsala Dissertations from the Faculty of Science and Technology, 2017.

${ }^{12}$ Pintrich PR. The role of motivation in promoting and sustaining self-regulated learning. Int $\mathbf{J}$ Educ Res. 1999;31(6):459-70.

${ }^{13}$ Pintrich PR, De Groot EV. A motivational science perspective on the role of student motivation in learning and teaching contexts. J Educ Psychol. 2003;95(4):667-86.

${ }^{14}$ Ramo NL, Huang-Saad A, Belmont B. What is biomedical engineering? Insights from qualitative analysis of definitions written by undergraduate students. In: ASEE annual conference and exposition, Tampa, Florida, 2019.

${ }^{15}$ Rule A. The components of authentic learning. J Authent Learn. 2006;3(1):1-10.

${ }^{16}$ Schmedlen R, Adam M, Sulewski R, Donnell MO. A real introduciton to engineering and biotechnolgy. In: ASEE annual conference \& exposition, Honolulu, HI, 2007.

${ }^{17}$ Sheppard S, Jenison R. Examples of freshman design education. Int J Eng Educ. 1997;13(4):248-61.

${ }^{18}$ Springer EJ, Huang-Saad A. Understanding identity among biomedical engineering students and professionals understanding identity among biomedical engineering students and. In: ASEE annual conference \& exposition. Virtual conference, 2020.

Publisher's Note Springer Nature remains neutral with regard to jurisdictional claims in published maps and institutional affiliations. 